\title{
What happens to your practice if the worst was to happen?
}

\section{Wesleyan Financial Services Consultant, Lloyd Boston, ${ }^{1}$ shares his insights} and top considerations for practice owners and principal dentists when planning the legacy of your business.

W hat would happen with your business should you, or your practice partner, pass away is a somewhat taboo subject, one which is understandably shied away from when it comes to financial planning.

This is one of the most important financial planning areas in terms of protecting your legacy, your business and your family should the unthinkable happen.

\section{Risks as a practice partner}

There are really two essential questions you need to think about and plan around: what agreements are in place between your partners and you and how will they work to support you and your family?

The reality is, from my experience, that many practices don't have a robust partnership agreement in place and the practice instead operates on an expense sharing arrangement. This is where a large amount of the risk lies with the family and, on the other side of the coin, you as the partner of the business.

If your partner was no longer part of the business due to serious illness or death, do you have the financial ability to buy your partner's share of the practice or would you prefer the family of the deceased to sell their share? If it's up to the family to sell, the risk is that the share might be sold on to someone with very different visions for the business than you have.

In the case of your own death, the standard procedure if the partnership agreements in place aren't clear would be to fall back to the Partnership Act 1890, whereby your partner will automatically inherit that share of the business. This would mean your business, that may have had years' worth of investment on your part, is simply absorbed and your family left with nothing if you don't have any other financial assets that make up your legacy.

\section{Risks as an NHS contract holder}

What you think your NHS contract may be worth as part of your business might not be the same value if you were to die.

As an NHS contract holder, should you pass away, your contract may be recouped by the NHS and tendered out to another practice, leaving your family with no recourse. There are also your patients to consider: the goodwill they may have had towards you as their dentist and what happens to their care. In this situation, it may be prudent not to rely on your family's ability to sell the practice with the NHS contract intact.
Now, to balance this, the NHS will likely have a vested interest in keeping the NHS contract at the existing address due to the desire to keep NHS patients in a local practice. If the survivors of the deceased are able to sell the practice with the NHS contract intact, it can become somewhat of

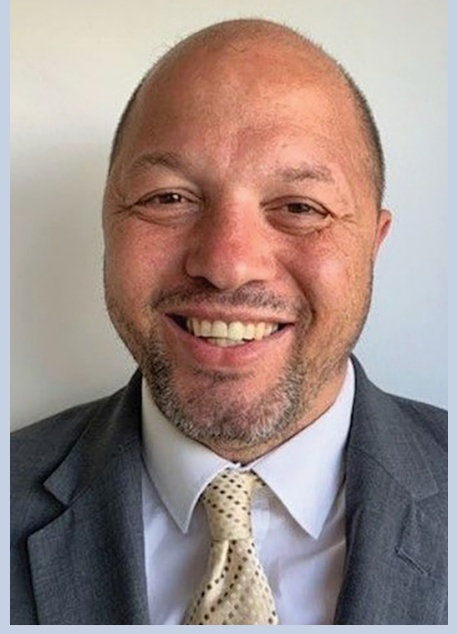

Lloyd Boston a fire-sale, where they have a limited amount of time to sell and may not recoup the full value.

Should the NHS pull back the contract, you are essentially left with a squat practice, where many of the patients will have no choice but to seek alternative NHS care elsewhere or pay private fees (which is unlikely without the goodwill), which reduces the value of the business. Even NHS practices that have a high level of private dental income could see a significant reduction in value by losing the NHS brand and its associated income.

\section{How do you mitigate these risks?}

A key area of mitigation is to look at your contract structure and what this will mean to the family of the deceased or seriously ill.

There are many clauses that make your circumstances unique when it comes to the future of your practice. Whether you have a cross option, first option or a mandatory buy-out agreement, going over the specifics with a fine tooth comb is crucial.

Sometimes the consequences of certain agreements and the clauses within them may be difficult to grasp, so it may be prudent in these circumstances to seek specialist advice from a financial consultant. This allows you to discuss your options and begin a plan of action if any of the agreement clauses are flagged as an issue which may scupper your financial aspirations for the future.

It may be that you require certain types of cover, building up your financial assets to offset potential risks or perhaps a more out-ofthe-box plan to support your family's future.

If you'd like to discuss your position and the future of your business, you can book a no-obligation financial review with a specialist Wesleyan Financial Services Consultant at www.wesleyan.co.uk/dental. Alternatively, you can call 08003163784. 